\title{
Effect of Estradiol and Steroid Analogues on the Clearance of Immunoglobulin G-coated Erythrocytes
}

\author{
David Friedman, Francis Nettl, and Alan D. Schreiber \\ Hematology-Oncology Section, Department of Medicine, Hospital of the University of Pennsylvania, Philadelphia, Pennsylvania 19104
}

\begin{abstract}
Although the disproportionate frequency of several immunologic disorders among women is well recognized, the effect of sex steroids on immunologic processes is unclear. We used an animal model, which has helped to elucidate the effect of corticosteroids in vivo, to quantitatively assess the effect of estradiol and steroid analogues on the immune clearance of IgG-coated erythrocytes. While corticosteroids impaired the clearance of IgG-coated erythrocytes, estradiol, in doses comparable to those achieved during pregnancy, significantly enhanced the clearance. Estradiol, however, did not enhance the splenic clearance of heat-altered erythrocytes. Splenic macrophages isolated from estradiol-treated animals expressed enhanced receptor activity for the Fc portion of immunoglobulin G [Fc(IgG)], an effect probably responsible for the enhanced in vivo clearance. No consistent effect of estradiol on the splenic macrophage $\mathrm{C} 3$ receptors was observed. The synthetic androgen danazol, the mineralocorticoid deoxycorticosterone, and the cortisol metabolite tetrahydrocortisone did not alter the clearance of IgG-coated cells after $7 \mathrm{~d}$ of therapy. The estrogen antagonist/agonist tamoxifen enhanced the clearance of IgG-coated cells, but to a lesser extent than estradiol. An effect of estrogens on macrophage Fc (IgG) receptor-mediated clearance may explain in part the variation in clinical expression of several autoimmune disorders during changes in hormonal state, such as pregnancy.
\end{abstract}

\section{Introduction}

Corticosteroids can substantially alter the course of immunologic disease, and their therapeutic use is widespread. Other steroid hormones, such as sex steroids, also seem to be associated with changes in the clinical expression of several immunologic disorders. Immune hemolytic anemia, immune thrombocytopenic purpura (ITP), ' and systemic lupus erythe-

This work was presented in part at the national meeting of the American Society of Hematology, San Francisco, CA, December 1983.

Address correspondence to Dr. Schreiber, University of Pennsylvania School of Medicine, Hematology/Oncology Section, 3400 Spruce St., Philadelphia, PA 19104.

Received for publication 22 December 1983 and in revised form 20 July 1984.

1. Abbreviations used in this paper: $\mathrm{cpm}_{\mathrm{c}}$, $\mathrm{cpm}$ for the untreated control animal injected with unsensitized cells; $\mathrm{cpm}_{\mathrm{x}}, \mathrm{cpm}$ for the experimental animal treated with steroid and injected with IgG-coated erythrocytes; Fc (IgG), Fc portion of immunoglobulin G; ITP, immune thrombocytopenic purpura; SSV, steroid suspension vehicle.

J. Clin. Invest.

(c) The American Society for Clinical Investigation, Inc. 0021-9738/85/01/0162/06 $\$ 1.00$

Volume 75, January 1985, 162-167 matosus all occur more frequently in women than in men. Furthermore, the clinical course of exacerbation and remission in patients with these diseases may vary with changes in hormonal state, such as during pregnancy and the immediate post-partum period (1-3).

One mechanism of corticosteroid action is the impairment of macrophage recognition of IgG-coated cells or IgG-containing immune complexes (4). Observations in murine models suggest that sex hormones may also affect macrophage function (5, 6). Recent studies in patients with ITP and immune hemolytic anemia demonstrate some beneficial effect from danazol, a synthetic androgen $(7,8)$. In addition, estrogen metabolism reportedly is altered in systemic lupus erythematosus patients in a manner that produces increased estrogenic activity (9). Despite these observations, the precise effect of sex steroids on immunologic processes is poorly understood.

We studied the effect of several steroid analogues, including sex steroids, on one aspect of the pathologic process in immune hemolytic anemia and ITP-splenic macrophage clearance of IgG-coated cells. We used an experimental model developed in the guinea pig, which we previously found helpful in elucidating the effect of corticosteroids on macrophage clearance of antibody and complement-coated erythrocytes $(10,11)$. Our data indicate that splenic macrophage receptor expression for the Fc portion of immunoglobulin $\mathrm{G}[\mathrm{Fc}(\mathrm{IgG})]$ is modulated not only by corticosteroids, but by estradiol as well.

\section{Methods}

Female Hartley guinea pigs weighing 500-600 g were obtained from Dutchland Farms, Denver, PA. All studies were done with females except as noted. Steroid drugs were obtained from Steraloids, Inc. (Wilton, NH), except for danazol (Sterling Drug, Inc., New York, NY), and tamoxifen (Stuart Pharmaceuticals Div., Wilmington, DE), which were kindly supplied by the manufacturers. All animals were injected with an equal volume of a homogeneous suspension of steroid in a vehicle (SSV) consisting of $0.5 \%$ carboxymethylcellulose, $0.4 \%$ Tween 80 , and $1.5 \%$ ethanol in isotonic saline. This suspension vehicle has been used in other laboratories for subcutaneous injection in animal models to examine the biologic effects of steroids (12). Sham-treated animals received $1 \mathrm{ml}$ of SSV alone, and the drug-treated animals received steroids suspended in SSV, injected subcutaneously in the dorsal neck fat pad every afternoon for $7 \mathrm{~d}$. Each animal was studied on the day after the seventh injection. IgG anti-guinea pig erythrocyte antibody was prepared in rabbits and quantitated as previously described (10). The IgG fraction was isolated by Sephadex G-200 chromatography and was free of IgM as determined by Ouchterlony analysis.

Clearance of IgG-coated erythrocytes. This model is identical to that previously reported by us (10). Blood was drawn from guinea pigs by cardiac puncture and the washed erythrocytes were radiolabeled with ${ }^{51} \mathrm{Cr}$-sodium chromate (New England Nuclear, Boston, MA) and then sensitized with an equal volume of IgG antibody, so as to be coated with 6,000 IgG molecules per erythrocyte. At least 1,500 IgG molecules per erythrocyte were necessary to accelerate clearance, similar to our previous observation $(10,13)$. The number of IgG molecules per erythrocyte was determined as previously described (10) 
after radiolabeling of the IgG fraction with ${ }^{125}$ I (14). Animals pretreated with steroid or SSV control for $7 \mathrm{~d}$ were injected intravenously with $2.7 \times 10^{8}$ radiolabeled cells. Samples of blood were obtained from the retroorbital space 5-120 min after injection and were counted using a gamma counter (Gamma 8000, Beckman Instruments, Inc., Fullerton, CA).

Studies were also performed with heat-altered erythrocytes to investigate splenic clearance mediated by nonimmune mechanisms. ${ }^{51} \mathrm{Cr}$-labeled erythrocytes were incubated for either 15 or $20 \mathrm{~min}$ at $50^{\circ} \mathrm{C}$ in parallel with control erythrocytes incubated for the same time period at $37^{\circ} \mathrm{C}$. The cells were then placed at $37^{\circ} \mathrm{C}$ for $5 \mathrm{~min}$ and then washed. The clearance of these heat-altered, radiolabeled erythrocytes was determined in the same way as the clearance of IgG-coated erythrocytes.

To determine the organ responsible for the clearance of sensitized and heat-altered erythrocytes, guinea pigs were sacrificed after the clearance studies. Their livers, kidneys, lungs, and spleens were removed, and whole organ ${ }^{51} \mathrm{Cr}$ radioactivity was determined in a gamma counter.

Clearance curves were plotted by expressing the number of blood cpm at each time point as a percentage of the number of cpm at 5 min. Clearance at time points 60,90 , and $120 \mathrm{~min}$ was analyzed to calculate a $\boldsymbol{P}$ value for the difference between control and experimental clearance curves using a Student's $t$ test. In addition, for each day's clearance study, the percentage inhibition of clearance above control was calculated at 90 and $120 \mathrm{~min}$ according to the formula: percent inhibition $=100 \times\left[1-\left(\mathrm{cpm}_{\mathrm{c}}-\mathrm{cpm}_{\mathbf{x}}\right) /\left(\mathrm{cpm}_{\mathrm{c}}-\mathrm{cpm}_{\mathrm{ea}}\right)\right]$, where $\mathrm{cpm}_{\mathrm{c}}$ refers to $\mathrm{cpm}$ for the untreated control animal injected with unsensitized cells, $\mathrm{cpm}_{\mathrm{x}}$ to the experimental animal treated with steroid and injected with IgG-coated erythrocytes, and $\mathrm{cpm}_{\mathrm{ea}}$ to control animals treated with SSV only (no steroid) and injected with IgG-sensitized erythrocytes. A negative value for percent inhibition indicates enhancement of clearance. This formula compares treated animals with the control animals studied on the same experimental day, and expresses the data as a percent alteration of clearance, where $100 \%$ inhibition of clearance by steroid corresponds to the situation in which the clearance of IgGsensitized erythrocytes $\left(\mathrm{cpm}_{\mathrm{x}}\right)$ is identical to that of unsensitized erythrocytes $\left(\mathrm{cpm}_{\mathrm{c}}\right)$.

Serum was drawn from several animals before and after 7-d courses of $1 \mathrm{mg} / \mathrm{kg}$ of estradiol per day. Serum was also drawn at parallel times from sham-treated controls. Estradiol levels were graciously determined in the clinical laboratory of Dr. Jerome Strauss at the University of Pennsylvania, using standard radioimmunoassay technology $(15,16)$.

Binding of IgG-coated erythrocytes by splenic macrophages in vitro. Guinea pigs were sacrificed, splenectomy performed immediately, and the spleens placed in Hanks' balanced salt solution (HBSS). Fine suspensions of spleen cells free of erythrocytes were obtained using tissue grinding sieves with a $150-\mu \mathrm{m}$ mesh, followed by brief incubation in hypotonic medium (17). The cells were then washed at $4^{\circ} \mathrm{C}$ and resuspended to $50 \mathrm{ml}$ in a cold $5 \%$ solution of heat-inactivated fetal calf serum in HBSS. $>90 \%$ of cells were viable mononuclear cells using trypan blue exclusion. Monolayers of adherent cells (>95\% capable of latex phagocytosis) were then prepared as previously described by incubating $5 \times 10^{6}$ mononuclear cells on a glass coverslip in a 35$\mathrm{mm}$ plastic petri dish at $37^{\circ} \mathrm{C}$ for $90 \mathrm{~min}$ under $5 \% \mathrm{CO}_{2}$ (18). Nonadherent cells were removed by washing with HBSS.

For experiments studying Fc (IgG) receptor activity, guinea pig erythrocytes were coated with 200,400 , and 800 molecules of IgG/ erythrocyte, as described above, and $1 \mathrm{ml}$ of erythrocytes at a concentration of $1 \times 10^{8}$ cells $/ \mathrm{ml}$ was incubated with the macrophage monolayers at room temperature for $\mathbf{4 5} \mathrm{min}$. For experiments studying C3 receptor activity, guinea pig erythrocytes were first sensitized with three different concentrations of IgM anti-guinea pig erythrocyte antibody $\left(20-90 \mu \mathrm{g} / 10^{8}\right.$ erythrocytes), washed, and incubated with guinea pig serum as a complement source for $15 \mathrm{~min}$ at $37^{\circ} \mathrm{C}$. $1 \mathrm{ml}$ of these C3coated, washed erythrocytes $\left(1 \times 10^{8} \mathrm{cells} / \mathrm{ml}\right)$ was then incubated with the macrophage monolayers as above. The monolayers were washed, air dried, stained with Wright-Giemsa, and 100 consecutive macrophages were inspected under oil immersion for the number of erythrocytes bound to each macrophage (18). Both the average number of erythrocytes bound per macrophage and the percentage of macrophages having three or more erythrocytes bound were determined.

The ability of soluble guinea pig IgG to inhibit splenic macrophage binding of IgG-coated erythrocytes was also studied. $1 \mathrm{ml}$ of guinea pig IgG (Calbiochem Behring Corp., San Diego, CA), not possessing anti-guinea pig erythrocyte antibody activity, at concentrations from 0.1 to $100 \mu \mathrm{g} / \mathrm{ml}$, was added to the macrophage monolayer just before incubation with IgG-coated erythrocytes, as described above. After incubation, the monolayers were washed and the average number of erythrocytes bound per macrophage and the percentage of macrophages having three or more erythrocytes bound were determined as above.

\section{Results}

Cortisol-pretreated guinea pigs exhibited impaired splenic clearance of IgG-coated erythrocytes. Pretreatment for 5-7 d with $90 \mathrm{mg} / \mathrm{kg}$ of cortisol impaired the clearance of IgG-coated erythrocytes in $19 / 26$ animals by $40 \pm 6 \%$ compared with simultaneous sham-treated controls (Fig. $1 A$ ). At $2 \mathrm{~h}, 60 \pm 2 \%$ of the IgG-coated erythrocytes remained in the circulation in cortisol-treated animals, compared with $50 \pm 4 \%$ in shams. These results confirm the ability of corticosteroids to inhibit the clearance of IgG-coated erythrocytes (11).

Guinea pigs pretreated with estradiol, however, exhibited enhanced splenic clearance of IgG-coated erythrocytes, an effect opposite to that of cortisol (Fig. $1 \mathrm{~A}$ ). Pretreatment for $7 \mathrm{~d}$ with $90 \mathrm{mg} / \mathrm{kg}$ of estradiol enhanced the clearance of IgGcoated erythrocytes in $10 / 12$ animals by $60 \pm 22 \%$ over simultaneous sham-treated controls. Only $31 \pm 6 \%$ of the IgG-coated cells remained in the circulation at $2 \mathrm{~h}$, compared with $50 \pm 4 \%$ for sham controls. In 3 of 12 estradiol-treated animals, clearance was enhanced so that $<10 \%$ of the IgG-coated erythrocytes remained in the circulation at $2 \mathrm{~h}$. The difference between the clearance curves for the estradiol-treated and sham-treated groups of animals was significant at a level of $P<0.001$.

This ability of estradiol to enhance the clearance of IgGcoated erythrocytes depended on the amount of estradiol with which the animals were treated. Estradiol at doses of 90, 10, and $1 \mathrm{mg} / \mathrm{kg}$ given for $7 \mathrm{~d}$ to groups of 12,6 , and 8 animals, respectively, enhanced the clearance of IgG-coated erythrocytes to a similar extent (Fig. $1 \mathrm{~B}$ ). The percentages of cells remaining in the circulation at $2 \mathrm{~h}$ were $31 \pm 6 \%, 23 \pm 8 \%$, and $27 \pm 6 \%$, respectively, compared with $50 \pm 4 \%$ for the sham-treated controls. Doses of 0.1 and $0.001 \mathrm{mg} / \mathrm{kg}$ of estradiol given to groups of eight animals each for $7 \mathrm{~d}$ did not alter the clearance. Serum levels of estradiol were measured in male and female animals before and after $7-d$ treatment with $1 \mathrm{mg} / \mathrm{kg}$ of estradiol, the lowest dose at which an enhancement of clearance was demonstrated. Estradiol levels were also measured in sham-treated controls. Pretreatment estradiol levels in both males and females were from 10 to $56 \mathrm{pg} / \mathrm{ml}$. Estradiol levels after sham treatment ranged from 10 to $69 \mathrm{pg} / \mathrm{ml}$ in males and females, but after treatment with estradiol, they ranged from 2 to $16 \mathrm{ng} / \mathrm{ml}$, a thousandfold increase similar to the rise and absolute blood level of estradiol observed during pregnancy, where estradiol levels are in the range of $20-30 \mathrm{ng} / \mathrm{ml}$ $(15,16)$.

Clearance of IgG-coated erythrocytes in the estradiol-treated and sham-treated animals was predominantly in the spleen (data not shown). No difference in clearance of IgG-sensitized 


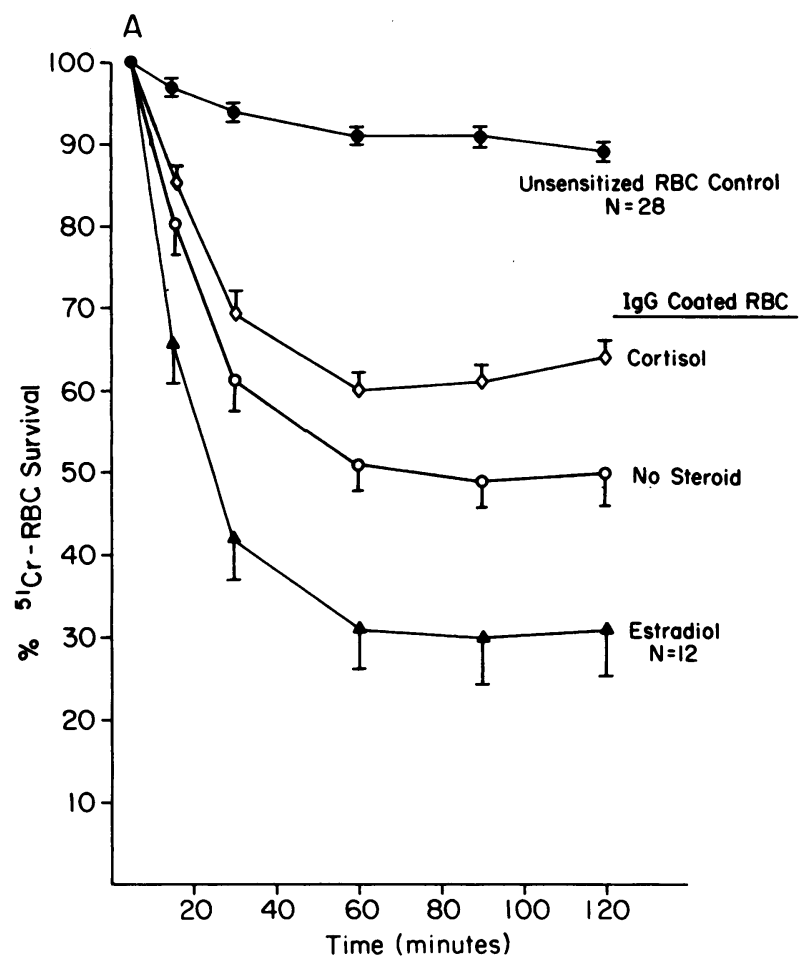

Figure 1. Clearance of IgG-coated erythrocytes $(\mathrm{RBC})$ in guinea pigs pretreated with cortisol $(n=19)$, estradiol $(n=12 ; P<0.001)$, or no steroid $(n=52)$. $(A)$ Animals were pretreated with $90 \mathrm{mg} / \mathrm{kg}$ per day

cells was observed between estradiol-treated males and females, or between sham-treated males and females, nor in clearance of unsensitized cells between untreated males and females.

Four other steroids or steroid analogues were examined for their effects on the splenic clearance of IgG-coated erythrocytes (Table I). Tamoxifen, a synthetic anti-estrogenic steroid, enhanced the clearance of IgG-coated erythrocytes in 8/12 animals, but to a lesser degree than estradiol. The mean enhancement of clearance for all 12 animals treated for $7 \mathrm{~d}$ was $28 \pm 18 \%$ over simultaneous controls. The other three steroids exhibited no consistent effect on the clearance of IgGcoated cells. Danazol, a synthetic androgen, given to 28

Table I. Effects of Steroid Analogues on Splenic Macrophage Clearance of IgG-coated Erythrocytes

\begin{tabular}{lll}
\hline Steroid & Dose & Enhanced clearanceł \\
\hline & $m g / k g$ & mean $\%$ \\
Danazol $(n=28)^{*}$ & $1-90$ & $4 \pm 17$ \\
Deoxycorticosterone $(n=11)$ & 90 & $2 \pm 20$ \\
Tetrahydrocortisone $(n=12)$ & 90 & $11 \pm 11$ \\
Estradiol $(n=26)^{*}$ & $1-90$ & $73 \pm 14$ \\
Tamoxifen $(n=12)^{*}$ & 90 & $28 \pm 18$
\end{tabular}

- Danazol did not alter clearance at dosages of $1(n=12), 10(n$ $=12)$, or $90(n=4) \mathrm{mg} / \mathrm{kg}$. Estradiol enhanced the clearance in $23 /$ 26 animals studied and tamoxifen in 8/12 animals studied. All animals were treated for $7 \mathrm{~d}$ before the clearance study.

¥ Determined from 120-min clearance values and includes all animals in each group.

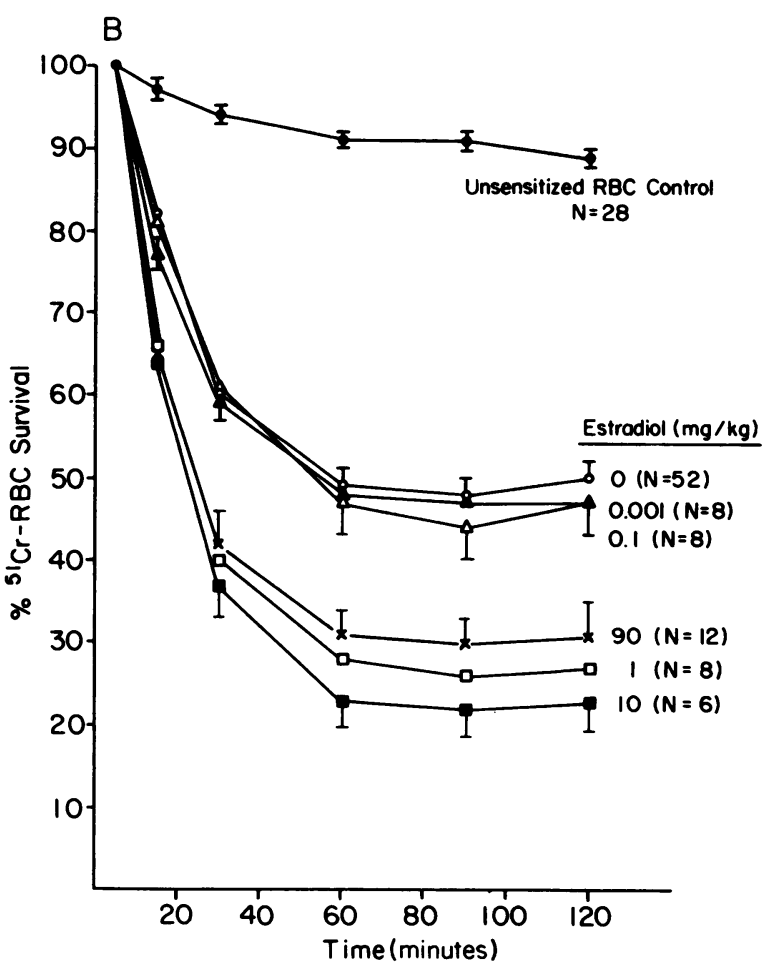

of steroid for $7 \mathrm{~d}$. (B) The dose-dependent effect of estradiol compared with the sham-treated controls $(-0-, n=52)$.

animals at doses from 1 to $90 \mathrm{mg} / \mathrm{kg}$ for $7 \mathrm{~d}$, altered the clearance of IgG-coated cells by $4 \pm 17 \%$, neither enhancing nor impairing clearance consistently. Deoxycorticosterone, a naturally occurring mineralocorticoid, given to 11 animals for $7 \mathrm{~d}$ at a dose of $90 \mathrm{mg} / \mathrm{kg}$, also had no consistent effect on clearance of IgG-coated erythrocytes $(2 \pm 20 \%)$. Similarly, tetrahydrocortisone, a reduced urinary metabolite of cortisol, given to 12 animals for $7 \mathrm{~d}$, did not affect clearance $(11 \pm 11 \%)$ (Table I).

To determine whether the effect of estradiol on clearance of IgG-coated erythrocytes was due to an effect on immunemediated splenic clearance, or was due to a more general effect on the splenic macrophage or splenic blood flow, we measured the clearance of heat-altered erythrocytes in estradiol-treated and sham-treated animals (Fig. 2). ${ }^{51} \mathrm{Cr}$-labeled guinea pig erythrocytes heated to $50^{\circ} \mathrm{C}$ for either 15 or $20 \mathrm{~min}$ were cleared in the spleen in a similar manner to IgG-coated erythrocytes. The percentage of cells in the circulation fell progressively over $2 \mathrm{~h}$, and the rate of clearance was dependent on the length of time the cells were heated. ${ }^{51} \mathrm{Cr}$ quantitation in whole spleen, liver, kidneys, and lungs indicated that clearance also took place predominately in the spleen. Estradiol did not enhance the splenic clearance of heat-altered erythrocytes, as it did the clearance of IgG-coated erythrocytes.

Finally, we examined the effect of estradiol administered in vivo on the expression of Fc (IgG) receptor activity and C3 receptor activity by isolated splenic macrophages in vitro. Guinea pigs were treated for $7 \mathrm{~d}$ with $1-10 \mathrm{mg} / \mathrm{kg}$ of estradiol, or they received sham treatment without steroid. Their spleens were removed and splenic macrophage monolayers were prepared. Estradiol treatment had no consistent effect on the yield 


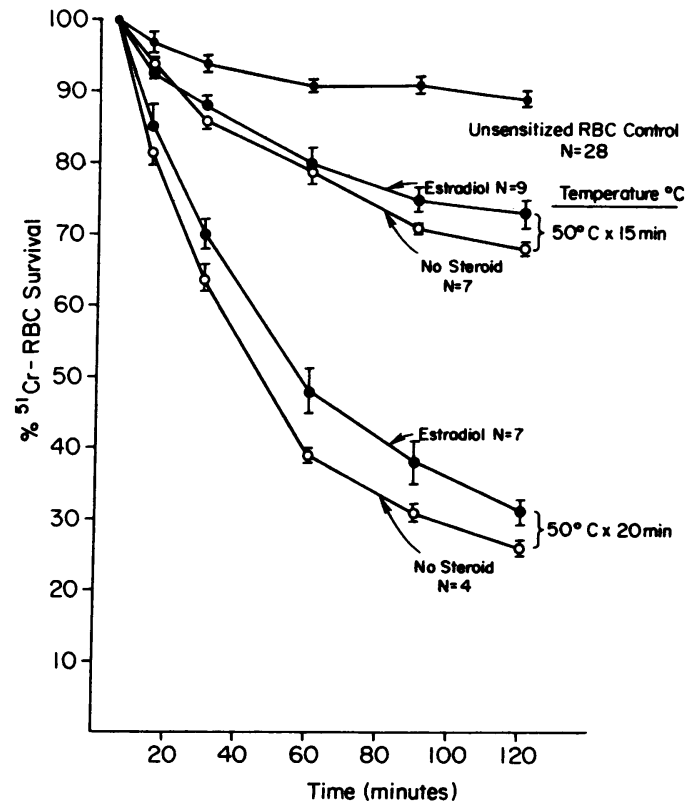

Figure 2. Clearance of heat-altered erythrocytes (RBC) in guinea pigs pretreated with estradiol. Erythrocytes were heated to $50^{\circ} \mathrm{C}$ for 15 or $20 \mathrm{~min}$ and injected into estradiol-treated animals $(90 \mathrm{mg} / \mathrm{kg}$ per day for $7 \mathrm{~d}$ ) or sham-treated controls.

or viability of mononuclear cells isolated from the spleen. $\mathrm{Fc}$ (IgG) receptor activity and C3 receptor activity were determined in two ways; first, by calculating the mean number of sensitized erythrocytes bound per macrophage, and second, by calculating the percentage of macrophages binding three or more sensitized erythrocytes (Table II). With increasing amounts of IgG/ erythrocyte, both the number of macrophages binding three or more erythrocytes and the average number of erythrocytes bound per macrophage increased. At all levels of IgG sensitization, in five of five separate experiments, splenic macrophages from estradiol-treated animals bound more IgG-coated erythrocytes than did macrophages from sham-treated controls. Furthermore, a greater percentage of the macrophages from the estradiol-treated animals bound three or more IgG-coated erythrocytes than did macrophages from sham-treated animals. Estradiol also seemed to have a slight enhancing effect on the nonspecific binding of unsensitized erythrocytes by splenic macrophages. We also examined the ability of soluble IgG to inhibit splenic macrophage binding of erythrocytes coated with $800 \mathrm{IgG}$ molecules/erythrocyte. Inhibition by soluble monomeric IgG was observed with macrophages from both shamtreated and estradiol-treated animals. In three of three experiments, IgG $(1.0-50 \mu \mathrm{g} / \mathrm{ml})$ more readily inhibited the binding of IgG-coated erythrocytes to the sham-treated animals. $50 \mu \mathrm{g} /$ $\mathrm{ml}$ of IgG inhibited the binding by macrophages isolated from estradiol-treated animals $45 \pm 10 \%$ compared with $76 \pm 6 \%$ inhibition of binding by macrophages isolated from sham-treated controls.

We also analyzed splenic macrophages for their $\mathrm{C} 3$ receptor expression. In contrast to the effect on the macrophage Fc (IgG) receptors, estradiol treatment in vivo did not consistently affect in vitro splenic macrophage binding of complement (C3)-coated erythrocytes. This was true whether the percent macrophages binding three or more C3-coated erythrocytes or
Table II. Effect of In Vivo Estradiol on Isolated Splenic Macrophage IgG (Fc) Receptor Activity

\begin{tabular}{|c|c|c|c|c|c|}
\hline \multirow[b]{2}{*}{$\begin{array}{l}\text { Experi- } \\
\text { ment }\end{array}$} & \multirow[b]{2}{*}{$\begin{array}{l}\text { IgG/ } \\
\text { erythrocyte }\end{array}$} & \multicolumn{2}{|l|}{ Sham control } & \multicolumn{2}{|l|}{ Estradiol } \\
\hline & & $\begin{array}{l}\text { Mean } \\
\text { erythrocytes/ } \\
\mathbf{M}^{*}\end{array}$ & $\begin{array}{l}\text { Percent } M^{*} \\
\text { binding } \geq 3 \\
\text { erythrocytes }\end{array}$ & $\begin{array}{l}\text { Mean } \\
\text { erythrocytes/ } \\
\mathbf{M}^{*}\end{array}$ & $\begin{array}{l}\text { Percent } M^{*} \\
\text { binding } \geq 3 \\
\text { erythrocytes }\end{array}$ \\
\hline \multirow[t]{4}{*}{1} & 0 & 0.6 & 0 & 0.3 & 3 \\
\hline & 200 & - & - & - & - \\
\hline & 400 & 1.8 & 30 & 4.4 & 75 \\
\hline & 800 & 3.2 & 57 & 4.6 & 74 \\
\hline \multirow[t]{4}{*}{2} & 0 & 0.2 & 1 & 0.4 & 5 \\
\hline & 200 & 0.1 & 0 & 1.3 & 18 \\
\hline & 400 & 0.4 & 6 & 1.2 & 15 \\
\hline & 800 & 2.3 & 39 & 3.7 & 57 \\
\hline \multirow[t]{4}{*}{3} & 0 & 0.1 & 2 & 0.3 & 3 \\
\hline & 200 & 0.1 & 1 & 1.4 & 20 \\
\hline & 400 & 0.8 & 11 & 2.9 & 47 \\
\hline & 800 & 0.8 & 13 & 2.9 & 46 \\
\hline \multirow[t]{4}{*}{4} & 0 & 0.3 & 3 & 1.0 & 14 \\
\hline & 200 & 1.8 & 29 & 4.5 & 70 \\
\hline & 400 & 3.2 & 52 & 5.3 & 81 \\
\hline & 800 & 3.3 & 53 & 5.1 & 81 \\
\hline \multirow[t]{4}{*}{5} & 0 & 0.6 & 0 & 0.5 & 7 \\
\hline & 200 & 0.6 & 5 & 1.3 & 17 \\
\hline & 400 & 1.1 & 17 & 2.6 & 38 \\
\hline & 800 & 2.1 & 35 & 3.9 & 62 \\
\hline
\end{tabular}

* M, macrophage.

the average number of erythrocytes bound per macrophage was determined (Table III).

\section{Discussion}

We employed an experimental animal model to define further the effect of steroid hormones on immune clearance. In these studies, we confirmed that pretreatment of guinea pigs with cortisol for $7 \mathrm{~d}$ impairs the splenic clearance of IgG-coated erythrocytes (11). Similar to the experience in man, we observed that not all animals respond to corticosteroids in this fashion. $7 \mathrm{~d}$ of corticosteroid treatment impaired the clearance of IgGcoated erythrocytes in $73 \%(19 / 26)$ of the animals studied.

In contrast to the effect of cortisol, the splenic clearance of IgG-coated erythrocytes in estradiol-pretreated animals was significantly enhanced (Fig. 1). This observation could be explained by estradiol increasing blood flow to the spleen, increasing the number of macrophages in the spleen, or altering recognition of IgG-coated erythrocytes by splenic macrophages. We observed that estradiol does not enhance the clearance of heat-altered erythrocytes, which have a pattern of splenic clearance similar to that of IgG-coated erythrocytes (Fig. 2). Furthermore, estradiol had no demonstrable effect on the small splenic clearance of erythrocytes not coated with IgG (not shown). The effect of estradiol, therefore, seems to be specific for immune-mediated clearance. If its effect was predominately to increase splenic blood flow or to increase the number or general activity of splenic macrophages, we 
Table III. Effect of In Vivo Estradiol on

Isolated Splenic Macrophage C3 Receptor Activity

\begin{tabular}{|c|c|c|c|c|c|}
\hline \multirow[b]{2}{*}{$\begin{array}{l}\text { Experi- } \\
\text { ment }\end{array}$} & \multirow[b]{2}{*}{$\begin{array}{l}\operatorname{lgM} \\
\left(\mu \mathrm{g} / 10^{8}\right. \\
\text { erythrocytes })\end{array}$} & \multicolumn{2}{|l|}{ Sham control } & \multicolumn{2}{|l|}{ Estradiol } \\
\hline & & $\begin{array}{l}\text { Mean } \\
\text { erythrocytes/ } \\
\mathbf{M}^{*}\end{array}$ & $\begin{array}{l}\text { Percent } M^{*} \\
\text { binding } \geq 3 \\
\text { erythrocytes }\end{array}$ & $\begin{array}{l}\text { Mean } \\
\text { erythrocytes/ } \\
\mathbf{M}^{*}\end{array}$ & $\begin{array}{l}\text { Percent } M^{*} \\
\text { binding } \geq 3 \\
\text { erythrocytes }\end{array}$ \\
\hline \multirow[t]{2}{*}{1} & 45 & 6.1 & 92 & 6.1 & 93 \\
\hline & 90 & 6.2 & 92 & 6.5 & 95 \\
\hline \multirow[t]{3}{*}{2} & 23 & 5.2 & 85 & 3.9 & 63 \\
\hline & 45 & 5.4 & 88 & 3.9 & 69 \\
\hline & 90 & 5.4 & 87 & 5.8 & 92 \\
\hline \multirow[t]{3}{*}{3} & 12 & 1.8 & 30 & 3.3 & 56 \\
\hline & 23 & 2.5 & 40 & 2.6 & 39 \\
\hline & 45 & 2.4 & 42 & 3.9 & 65 \\
\hline \multirow[t]{3}{*}{4} & 12 & 3.7 & 60 & 4.5 & 71 \\
\hline & 23 & 4.7 & 71 & 6.5 & 96 \\
\hline & 45 & 6.8 & 96 & 6.7 & 97 \\
\hline \multirow[t]{3}{*}{5} & 12 & 5.0 & 83 & 4.7 & 82 \\
\hline & 23 & 6.7 & 98 & 5.7 & 88 \\
\hline & 45 & 6.9 & 100 & 6.9 & 100 \\
\hline
\end{tabular}

* M, macrophage.

would have expected estradiol-treated animals to clear heataltered erythrocytes more rapidly than sham-treated controls.

The in vitro experiments employing splenic macrophages isolated from estradiol-pretreated animals further elucidate the mechanism of estradiol's action. The recognition of guinea pig erythrocytes by splenic macrophages depended upon the concentration of IgG on the erythrocyte surface. At a given concentration of IgG per erythrocyte, recognition of IgGcoated cells by splenic macrophages was increased in those macrophages isolated from estradiol-treated animals (Table II). Estradiol increased the average number of IgG-coated erythrocytes bound per macrophage, as well as the percent of macrophages binding at least three IgG-coated erythrocytes. The observation that both measurements of Fc (IgG) receptor activity increased suggests that estradiol augments Fc (IgG) receptor expression by populations of splenic macrophages that express $\mathrm{Fc}(\mathrm{IgG})$ receptors weakly, as well as by populations that express $\mathrm{Fc}(\mathrm{IgG})$ receptors more strongly before treatment.

The experiments using soluble guinea pig IgG to inhibit macrophage binding of IgG-coated erythrocytes begin to address the mechanism of estradiol's action. Tissue macrophages in several species express an Fc (IgG) receptor for aggregated IgG separate from that for monomeric IgG (19). Soluble monomeric IgG at concentrations $\geq 10 \mu \mathrm{g} / \mathrm{ml}$ substantially inhibited the binding of IgG-coated erythrocytes to macrophages from the estradiol-treated animals. Thus, the Fc (IgG) receptor for monomeric IgG is most likely important for the binding of IgG-coated erythrocytes by macrophages isolated from both estradiol-treated and from sham-treated animals. We observed that monomeric IgG decreased the binding of IgG-coated erythrocytes by macrophages from sham-treated animals more effectively than from estradiol-treated animals. If estradiol increases the number of receptors for monomeric IgG, we might expect monomeric IgG to decrease the binding of IgGcoated erythrocytes by macrophages from estradiol-treated and sham-treated animals more proportionately. Our data, therefore, may suggest an effect of estradiol on splenic macrophage receptor affinity for IgG monomer. However, definitive studies await the isolation of purified splenic macrophages in suspension and the analysis of equilibrium and reversible binding studies with monomeric IgG.

In this study we directly compared the ability of splenic macrophages to detect IgG-coated erythrocytes in vitro and in vivo. A much smaller number of IgG molecules per erythrocyte was required for macrophage detection of IgG-coated cells in vitro. This is consistent with our previous data with guinea pig macrophages in vivo (13) and human monocytes in vitro (18). This probably reflects the absence of IgG in the milieu during the in vitro studies and its presence in vivo in the spleen, although anatomic factors may also influence recognition by macrophages in vivo.

Taken together, the data indicate that pretreatment of guinea pigs for $7 \mathrm{~d}$ with $1-90 \mathrm{mg} / \mathrm{kg}$ of estradiol increases the Fc (IgG) receptor expression of splenic macrophages, and that this increase is responsible for the difference in the in vivo clearance of IgG-coated erythrocytes. The possibility remains that some of the effect of estradiol on clearance may be due to an estradiol-dependent increase of splenic macrophage $\mathrm{C} 3 \mathrm{~b}$ or iC $3 \mathrm{~b}$ (iC3b fragment of the third component of complement) receptor activity. IgG on the surface of the erythrocytes may activate complement in the guinea pig circulation. However, in vitro studies conducted with complement (C3)-coated erythrocytes in the absence of IgG indicate that estradiol pretreatment does not substantially enhance splenic macrophage $\mathrm{C} 3$ receptor activity. Thus, the effect of estradiol in increasing the clearance of IgG-coated cells seems to be predominately due to an effect on splenic macrophage Fc (IgG) receptor activity.

Vernon-Roberts (5) was among the first to systematically analyze the effect of steroid hormones on macrophage function. He observed that estrogen treatment of mice caused rapid hepatic uptake of carbon particles. Furthermore, during the reproductive cycle and pregnancy, macrophage phagocytic activity coincided with an increase in estrogen level. Although these experiments were conducted in the mouse, which, unlike the guinea pig and man, is especially sensitive to exogenous steroid hormones (20), these data also suggest that macrophage function may be affected by estrogens. Our data extend this observation to elucidate a specific effect of estradiol on splenic macrophage $\mathrm{Fc}(\mathrm{IgG})$ receptor expression, clearly linking estrogens to an effect on the immune system.

Hormonal manipulation has been observed to alter the course of the lupus-like syndrome in the NZB/NZW mouse (6). Estrogen treatment of these mice did not accelerate the clearance of IgG-coated erythrocytes. These studies differ from ours in that they were performed in a corticosteroid-sensitive species that produces autoantibodies and circulating immune complexes, whereas our studies were performed in normal guinea pigs, which, like man, are corticosteroid resistant. This species difference may also apply to other steroid hormones. Furthermore, the presence of circulating immune complexes may modulate the number of available splenic macrophage Fc (IgG) receptors (21).

Tamoxifen is a nonsteroidal antiestrogen used in the palliation of estrogen receptor-positive breast cancer. Its effect in animal models depends on species and end organ. Thus, it 
can be an estrogen agonist, antagonist, or a partial agonist/ antagonist (22). Our data suggest that tamoxifen acts as an estrogen agonist, less potent than estradiol, in influencing splenic macrophage Fc (IgG) receptor activity in normal guinea pigs. Whether tamoxifen inhibits or facilitates the effect of estradiol in this system is as yet unknown.

Recently, danazol, a synthetic androgen, has proven effective in some patients with immune thrombocytopenic purpura (7) or autoimmune hemolytic anemia (8). Its mechanism of action is uncertain. Our data suggest that danazol's effect after 1 wk of treatment would be due to a mechanism other than an alteration of splenic macrophage recognition of IgG-coated cells. However, danazol treatment longer than $7 \mathrm{~d}$ may have additional effects.

Our experiments defining the effect of estradiol may be applicable to human immunologic disease, since several such disorders are disproportionately common among women. The clinical manifestation of these diseases may increase in phase with the menstrual cycle and in pregnancy, where estrogen levels increase dramatically (1-3). In IgG-induced immune hemolytic anemia, disease activity seems more profound during the later stages of pregnancy when estrogen levels are at their highest (23). Estrogen-containing oral contraceptives have also been observed to exacerbate immune complex disease (24). The minimal effective estradiol dose $(1 \mathrm{mg} / \mathrm{kg}$ per day) and blood levels achieved $(2-16 \mathrm{ng} / \mathrm{ml})$ in our system are equivalent to the daily estrogen production and blood levels achieved during human pregnancy $(25,15,16)$. Our experimental design is patterned after pathologic processes in immune hemolytic anemia and immune thrombocytopenia. A direct effect of estrogens on splenic macrophage Fc (IgG) receptor-mediated clearance of IgG-coated erythrocytes or platelets may, in part, explain the variation in clinical expression of these disorders $(1-3,23,24,26)$ during changes in hormonal state, e.g., pregnancy.

These experiments raise the question of the effect of estrogens on other macrophage populations and on additional Fc (IgG) receptor-bearing cells that participate in the localization of immune complexes. Such an effect might also enhance the clinical expression of immune complex disease by augmenting macrophage interaction with circulating immune complexes or by increasing immune complex deposition in certain tissues.

\section{Acknowledgments}

The authors thank Diane Tate for her expert technical assistance in preparing this manuscript for publication. This work was supported by National Institutes of Health grants HL-28207 and CA-15236.

\section{References}

1. Peterson, O. H., Jr., and P. Larson. 1954. Thrombocytopenic purpura in pregnancy. Obstet. Gynecol. 4:454-469.

2. Goodhue, P. A., and T. S. Evans. 1962. Idiopathic thrombocytopenic purpura and pregnancy. Obstet. Gynecol. Surv. 18:671-693.

3. Zurier, R. B. 1983. SLE and pregnancy. In The Clinical Management of Systemic Lupus Erythematosus. P. Schur, editor. Grune \& Stratton, Inc./Orlando, FL. 221-220.

4. Schreiber, A. D. 1977. Clinical immunology of the corticosteroids. Prog. Clin. Immunol. 3:103-114.

5. Vernon-Roberts, B. 1969. The effects of steroid hormones on macrophage activity. Int. Rev. Cytol. 25:131-159.
6. Shear, H. L., J. R. Roubinian, P. Gil, and N. Talal. 1981. Clearance of sensitized erythrocytes in NZB/NZW mice: effects of castration and sex hormone treatment. Eur. J. Immunol. 11:776-780.

7. Ahn, Y. S., W. J. Harrington, S. R. Simon, R. Mylvaganam, L. M. Pall, and A. G. So. 1983. Danazol for the treatment of idiopathic thrombocytopenic purpura. N. Engl. J. Med. 308:1396-1399.

8. Ahn, Y. S., W. J. Harrington, R. Mylvaganam, L. Chua, J. Otoya, L. Pall, and G. Wang. 1983. Danazol therapy in autoimmune hemolytic anemia (AIHA). Blood. 62(Suppl):102a. (Abstr.)

9. Lahita, R. G., H. L. Bradlow, H. G. Kunkel, and J. Fishman. 1979. Alterations of estrogen metabolism in systemic lupus erythematosus. Arthritis Rheum. 22:1195-1198.

10. Schreiber, A. D., and M. M. Frank. 1972. Role of antibody and complement in the immune clearance and destruction of erythrocytes. I. In vivo effects of IgG and IgM complement-fixing sites. $J$. Clin. Invest. 51:575-582.

11. Atkinson, J. P., A. D. Schreiber, and M. M. Frank. 1973. Effects of corticosteroids and splenectomy on the immune clearance and destruction of erythrocytes. J. Clin. Invest. 52:1509-1517.

12. Dubin, W. E., B. J. Bowman, and R. O. Stafford. 1957. Effects of 2-Methylation on glucocorticoid activity of various C-21 steroids. Proc. Soc. Exp. Biol. Med. 94:303-305.

13. Schreiber, A. D., and M. M. Frank. 1972. Role of antibody and complement in the immune clearance and destruction of erythrocytes. II. Molecular nature of IgG and IgM complement-fixing sites and effects of their interaction with serum. J. Clin. Invest. 51:583-589.

14. Cines, D. B., and A. D. Schreiber. 1979. Immune thrombocytopenia: use of a Coombs antiglobulin test to detect IgG and C3 on platelets. N. Engl. J. Med. 300:106-111.

15. Townsley, J. D., N. H. Dubin, G. F. Grannis, L. J. Gartman, and C. D. Crystle. 1972. Circadian rhythms of serum and urinary estrogens in pregnancy. J. Clin. Endocrinol. Metab. 36:289-294.

16. Iwai, M., H. Kanno, M. Hashino, J. Suzuki, T. Yanaihara, and T. Nakayama. 1981. Determination of serum unconjugated estrone, estradiol-17B, and estriol during pregnancy by selected ion monitoring. J. Chromatogr. 225:275-282.

17. Weir, D. M. 1973. Handbook of Experimental Immunology. Blackwell Scientific Publications, Inc./Boston, MA. 24:17.

18. Schreiber, A. D., J. Parsons, P. McDermott, and R. A. Cooper. 1975. Effect of corticosteroids on the human monocyte IgG and complement receptors. J. Clin. Invest. 56:1189-1197.

19. Fleit, H. B., S. D. Wright, and J. C. Unkeless. 1982. Human neutrophil Fc receptor distribution and structure. Proc. Natl. Acad. Sci. USA. 79:3275-3270.

20. Claman, H. N. 1972. Corticosteroids and lymphoid cells. $N$ Engl. J. Med. 287:388-397.

21. Fries, L. F., M. Brickman, and M. M. Frank. 1983. Monocyte receptors for the $\mathrm{Fc}$ portion of IgG increase in number in autoimmune hemolytic anemia and other hemolytic states and are decreased by glucocorticoid therapy. J. Immunol. 131:1240-1245.

22. Patterson, J. S. 1981. Clinical aspects and development of anticestrogen therapy: a review of the endocrine effects of tamoxifen in animals and man. J. Endocrinol. 89:67P-75P.

23. Chaplin, H., Jr., R. Cohen, G. Bloomberg, H. J. Kaplan, J. A. Moore, and I. Dorner. 1973. Pregnancy and idiopathic autoimmune haemolytic anemia. A prospective study during 6 months gestation and 3 months post-partum. Br. J. Haematol. 24:219-229.

24. Jungers, P., M. Dougados, C. Pelissier, F. Kuttenn, F. Ton, P. Lesavre, and J. Bach. 1982. Influence of oral contraceptive therapy on the activity of systemic lupus erythematosus. Arthritis Rheum. 25:618623.

25. Pritchard, J. A., and P. C. MacDonald. 1980. Williams Obstetrics. Appleton-Century-Crofts/East Norwalk, CT. 161-163.

26. Jungers, P., M. Dougados, D. Pelissier, F. Kuttenn, F. Tron, P. Lesavre, and J. Bach. 1982. Lupus nephropathy and pregnancy: report of 104 cases in 36 patients. Arch. Intern. Med. 142:771-776. 